\title{
Physical inactivity in early pregnancy and the determinants in an urban city setting of Kuala Lumpur, Malaysia
}

\author{
Sharifah Fazlinda Syed $\operatorname{Nor}^{1,2}$ (D), Idayu Badilla Idris ${ }^{{ }^{*}}$ (D) and Zaleha Md Isa ${ }^{1}$ (1)
}

\begin{abstract}
Background: Physical inactivity in pregnancy has been associated with excessive gestational weight gain, hypertensive disorders, gestational diabetes mellitus and postpartum depression. Despite these risks, physical inactivity level remains high especially in higher income countries. The prevalence of physical inactivity among women in Malaysia aged $\geq 16$ years was $28.2 \%$ in 2019 exceeding men by $6.1 \%$. However, little is known regarding the subpopulation of pregnant women especially in Kuala Lumpur which is the most urbanized and highly populated city in Malaysia. Therefore, the aim of this study is to measure the physical inactivity prevalence among first trimester pregnant women in Kuala Lumpur and to identify its determining factors.
\end{abstract}

Methods: This was a cross-sectional study in which 339 first trimester pregnant women were sampled from 13 maternal and child health clinics located in all four parliament districts of Kuala Lumpur. Self-administered questionnaires which contained the Malay version of the pregnancy physical activity questionnaire (PPAQ) were used. Descriptive analysis was conducted to determine the physical inactivity prevalence followed by simple and multiple logistic regression to identify the determinants of physical inactivity with significant level of 5\%.

Results: The prevalence of physical inactivity was $38.3 \%$. The highest activity was seen in the household activity domain, despite only $24.8 \%$ of the respondents were housewives/unemployed. There was little to no participation observed in the vigorous intensity category. The determinants of physical inactivity were primigravida (aOR 3.54 95\% $\mathrm{Cl} 1.40,8.97)$, education level (aOR $3.7795 \% \mathrm{Cl} 1.35,10.52$ ) and body mass index (aOR $0.8895 \% \mathrm{Cl} 0.80,0.97$ ) which explained $22.6 \%$ variation of physical inactivity in the final adjusted model.

Conclusion: The prevalence of physical inactivity among first trimester pregnant mothers in this study was 38.3\%, and the highest activity was seen in the household category. Health education on physical activity in pregnancy should be focused on those who are primigravida and have no tertiary education. The educational content should be updated and tailored to current pandemic situation where self-isolation is the new norm, by advocating for homebased, moderate to vigorous intensity physical activities.

Keywords: Exercise, Pregnant women, Factors, First trimester, PPAQ

*Correspondence: idayubadilla.idris@ukm.edu.my

${ }^{1}$ Department of Community Health, Faculty of Medicine, Universiti Kebangsaan Malaysia, Jalan Yaacob Latif, Bandar Tun Razak, Batu 9 Cheras, 56000 Wilayah Persekutuan Kuala Lumpur, Malaysia

Full list of author information is available at the end of the article

\section{Background}

Physical activity can be defined as any movement produced by skeletal muscles that requires the use of energy [1]. It can be measured in metabolic equivalents (METs) [2]. As a reference, one metabolic equivalent of task (MET) equals the energy being used for sitting at rest [2]. 
The World Health Organization (WHO) recommends healthy adults to be involved in at least $150 \mathrm{~min}$ of moderate- to vigorous-intensity activity, which are activities of at least 3 METs, spread throughout the week [1]. This also applies to pregnant women because physical activity early in the first trimester and throughout the pregnancy [3] is not associated with increased odds for miscarriage or prenatal mortality [4]. Instead, it is strongly associated with reduced risks of excessive gestational weight gain, hypertensive disorders, gestational diabetes mellitus and postpartum depression [5-9].

Physical inactivity has been identified as one of the modifiable risk factors for non-communicable diseases in the general adult population; these diseases include cardiovascular disease, diabetes mellitus as well as certain cancers, among others [1]. It is also associated with mental health disorders such as depression [1]. Besides these morbidities, physical inactivity has also been identified as the fourth leading risk factor for mortality [10]. Global data have shown that physical inactivity is two times more prevalent in higher income countries compared with their low income counterparts, a phenomenon mostly attributed to rapid urbanisation, especially in the transportation network [11]. This phenomenon highlights the need for a more concerted effort to empower and promote physical activities and an active lifestyle among populations in developing and developed nations and cities around the world.

The overall global physical inactivity prevalence stood at $27.5 \%$ in 2016 . It is worth noting that at $31.7 \%$, the prevalence of physical inactivity in women exceeded the prevalence in men by $8.0 \%$. Latin America, the Caribbean and South Asia had the highest prevalence of physically inactive women [12]. During pregnancy, the prevalence of physical inactivity tends to be higher than the general female population because pregnant women tend to reduce their physical activity once they become pregnant [13-16]. Recent studies have reported that physical inactivity in pregnant women ranged from $21.9 \%$ to as high as $75.0 \%[15,17-21]$. The highest physical inactivity prevalence was seen among pregnant women in Oslo, Norway, and the lowest was seen among pregnant women in Tigray, Ethiopia [17, 19]. However, it is worth noting that different physical inactivity measurement methods and outcomes were applied in these studies. Similar to the global data of the general population, a lower prevalence of physical inactivity among pregnant women was found in lower income countries.

The overall prevalence of physical inactivity among the Malaysian population aged $\geq 16$ years was $25.1 \%$ in 2019 , down sharply from $33.5 \%$ in 2015 , as reported in the National Health and Morbidity Survey (NHMS) 2019 [22]. The criteria used in this survey to classify a person as physically active were similar to the criteria recommended by the WHO. Specifically, the criteria were people involved in at least $20 \mathrm{~min}$ of vigorous activity for three or more days in a week or $30 \mathrm{~min}$ of moderate activity for five or more days in a week or achieving a total of at least 600 MET-minutes of activity in a week [22]. The NHMS 2019 also revealed that physical inactivity was more prevalent in the urban populations and similar to the global data. Moreover, the prevalence of physical inactivity was higher among women $(28.2 \%)$ compared with men [22]. Despite these findings, the latest study by Su et al. [23] found only $17.3 \%$ of women in the low-income category in Kuala Lumpur were physically inactive.

There are no national data regarding physical inactivity specifically during pregnancy in Malaysia. However, the prevalence of physical inactivity is expected to be much higher in pregnant compared with non-pregnant women because women generally tend to reduce their physical activity once they become pregnant and as the pregnancy progresses $[13,15,16,24]$. It is also worth noting that physical activity in the first trimester may have the most positive impact on the well-being of the pregnancy as a whole, because not getting sufficient physical activity from the first trimester is highly associated with pregnancy complications such as gestational diabetes and hypertensive disorders [3, 25]. In addition, early initiation of physical activity in the first trimester has been linked to improved and greater sleep quality [26]. Although first trimester participation in sports and exercise was found to reduce the infant's birth weight, it did not increase the risk of delivering small for gestational age babies [27]. Therefore, early detection and identification of physical inactivity among pregnant women is vital so that early and timely interventions can be delivered to prevent pregnancy complications related to physical inactivity.

Individual factors that have commonly been associated with physical activity in pregnancy are parity or number of living children, education level, employment status and body mass index (BMI); maternal age, ethnicity and history of miscarriage have been considered less frequently $[15,17,19,20,28-33]$. Three studies have found that primiparity is significantly associated with physical inactivity $[17,19,30]$, while three other studies have found that multiparity is significantly associated with physical inactivity $[15,31,33]$. However, the measurement tools and outcomes of these studies were not the same and had not been standardised, perhaps explaining the contradictory findings.

Gebregziabher et al. [17] reported that those who had lower education levels were likely to be physically inactive compared with those who went to high school (aOR 19.4 95\% CI 4.9, 76.1). Similarly, a study in Serbia found 
that those with less than 12 years of formal education are twice as likely to be physically inactive compared with those who had more than 12 years of formal education (aOR 2.30 95\% CI 1.05, 5.04) [20]. Meanwhile, Nascimento at al [15]. found that those who went to college or a higher institution are three times more likely to be involved in physical activity during pregnancy (aOR 3.0, 95\% CI 2.0-4.5). However, two studies from Nigeria and Norway reported that education level is not significantly associated with physical activity levels [19, 31].

Previous findings regarding the association between BMI and physical activity levels have been inconclusive. However, most have found that higher BMI contributes to greater physical inactivity [19, 33, 34]. On the other hand, Santo et al. [35] found that underweight has an association with sufficient physical activity compared with a normal BMI. Studies from Brazil, Nigeria and Serbia have found no association between BMI and physical activity levels in pregnancy $[15,20,31]$, although Oyeyemi et al. [31] from Nigeria reported that the waist-to-hip ratio is a significant factor to predict a sufficient physical activity level.

Another factor that has been found to be associated with physical activity levels is the employment status or maternal occupation. Gebregziabher et al. [17] reported that farmers in Ethiopia were more likely to be associated with sufficient activity level compared with housewives. Oyeyemi et al. [31] found that businesswomen in Nigeria were more likely to be physically active. Nascimento et al. [15] found that those who were working were more likely to be physically active compared with those who were unemployed. Three other studies from Sweden, Norway and Serbia, however, did not find any association between employment status and the physical activity level [19, 20, 34].

Realizing the importance of reducing the risks of physical inactivity in pregnancy, this study was conducted with the aim to measure physical activity levels and determine the prevalence as well as the factors associated with physical inactivity among first trimester pregnant women in an urban city setting of Kuala Lumpur, Malaysia.

\section{Methods}

\section{Study design and background}

This cross-sectional study was conducted among the population of pregnant women in the Malaysian capital, the Federal Territory of Kuala Lumpur. This area was selected because it is $100 \%$ urbanised and the risk factors for a high prevalence of physical inactivity are present in the population $[11,12,22]$. This city comprises four distinct parliament districts, namely Cheras, Kepong, Titiwangsa and Lembah Pantai. An estimated 24,235 pregnant women resided in Kuala Lumpur in 2019, of whom $28.9 \%$ were in Kepong, $18.0 \%$ in Lembah Pantai, $32.6 \%$ in Titiwangsa and $20.5 \%$ in Cheras.

\section{Sampling and data collection}

We calculated the sample size by using the Power and Sample Size Program (PS version 3.1.2) software based on significant variables (parity, occupation, education level, BMI, history of miscarriage) from similar studies among pregnant women $[15,17,35]$, with $80 \%$ power and an alpha value of 0.05 ( $95 \% \mathrm{CI})$. The highest sample size calculated was 282 ; with the addition of $10 \%$ to anticipate non-response, the final required sample size was 310 . The respondents were conveniently sampled from 13 out of 24 government maternal and child health $(\mathrm{MCH})$ clinics in all four parliament districts of Kuala Lumpur on their first day of antenatal check-up (registration/booking day).

The inclusion criteria were Malaysian citizens aged $\geq 18$ years, first trimester or less than 13 weeks along in gestation (calculated from the date of last menstruation confirmed by ultrasound scan at booking), singleton pregnancy and able to read and speak in Malay or English. The exclusion criteria were multiple gestations (confirmed by ultrasound scan at booking), current medical illness (cardiovascular diseases, diabetes mellitus, anaemia, asthma etc.), physically or mentally disabled and $>40$ years old. The recommendation to be physically active by the WHO - 150 min of moderate to vigorous activities in a week - only applies to healthy pregnant women [1], which was the reason why high risk pregnancies (women $<18$ or $>40$ years old, physically and mentally disabled, multiple gestation pregnancies) and those who had existing medical illnesses were not included in this study.

The study flowchart is presented in Fig. 1. The respondents voluntarily participated. Once written consent was obtained, participants were given a questionnaire to complete. Data collection was conducted from July 2019 to August 2020.

\section{Study instrument}

This study used a self-administered questionnaire comprising five sections. Section A was on sociodemographic details, section $B$ was on anthropometric details, section $\mathrm{C}$ was on medical history, section D was on 24-h dietary recall and section $\mathrm{E}$ was the Malay version of the pregnancy physical activity questionnaire (PPAQ) [36], which was originally developed by Chasan-Taber et al. [37]. Section D was used to calculate caloric intake among respondents in a day. The PPAQ section contained a total of 32 items pertaining to physical activities in five different activity domains, namely household, sports/exercise, commuting, occupational and inactivity. 


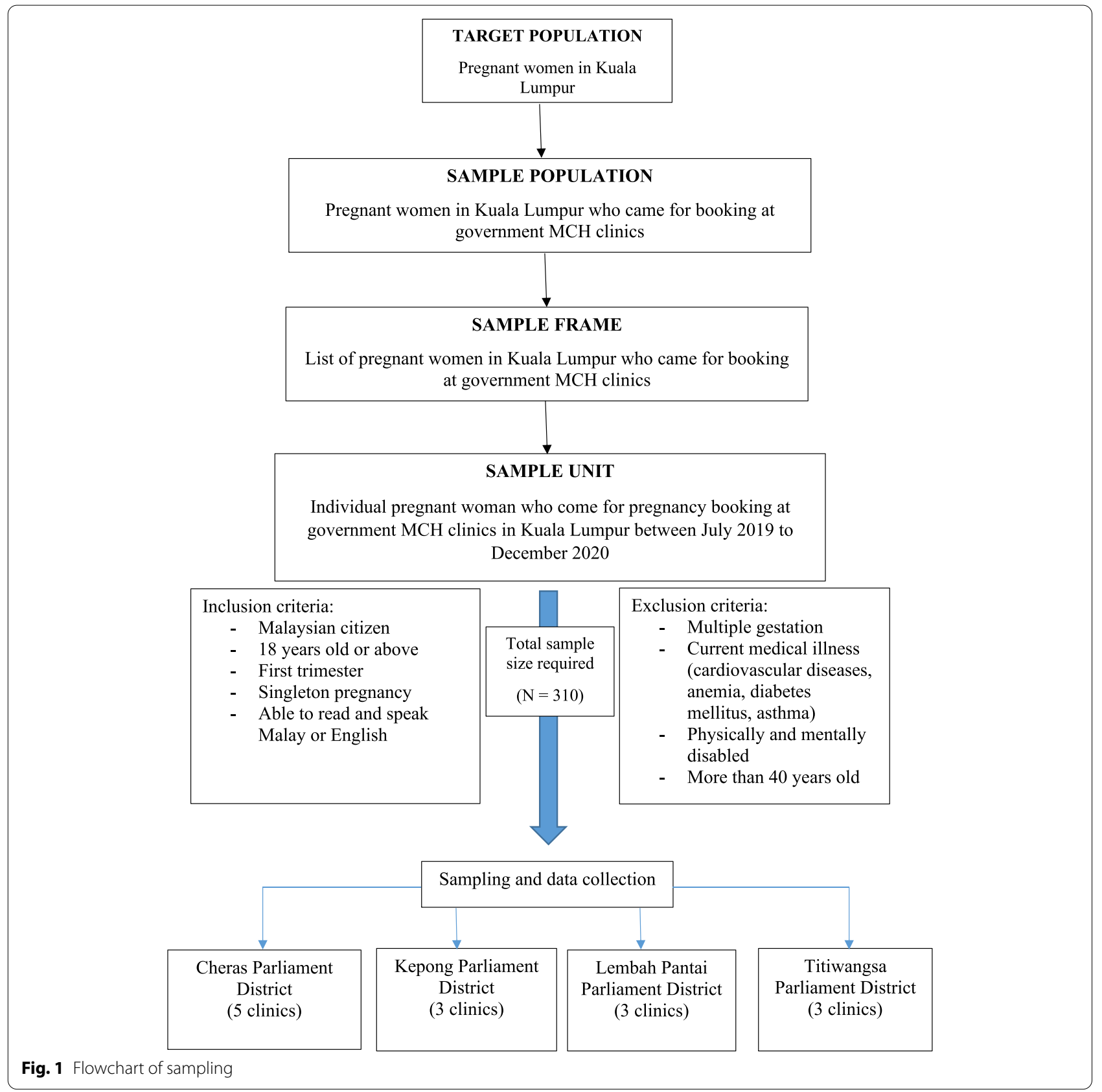

\section{Study variables}

The dependent variable in this study was physical inactivity. The independent variables were age, ethnicity, marital status, household income, education level, occupation, husband's occupation, primigravida, grand multigravida, caloric intake per day, BMI at booking, medical problem in previous pregnancy and history of miscarriage. The operational definition of each variable used in this study is presented in Table 1.

\section{Data analysis}

Data were first analysed by using descriptive analysis. Continuous data were presented as the mean \pm standard deviation (SD) or median and interquartile range (IQR) depending on the normality of the data distribution. Categorical data were presented as frequencies and percentages. Each of the respondent's 24-h dietary recall was converted into total caloric intake per day by referring to the calorie bank developed by the Nutrition 
Table 1 Operational definitions of variables

\begin{tabular}{|c|c|c|c|}
\hline No & Word/Phrase & Operational Definition & Measurement Scale \\
\hline 1 & $\begin{array}{l}\text { Physical inactivity } \\
\text { (Dependent variable) }\end{array}$ & Less than $7.5 \mathrm{METs}^{\mathrm{a} *}$ hour/week or 150 min of moderate to vigorous activities in a week [1] & Yes/No \\
\hline 2 & Age & Age at first antenatal booking based on identity card & Number in years \\
\hline 3 & Marital status & Marital status verified by a legal marriage certificate & $\begin{array}{l}\text { Married } \\
\text { Unmarried }\end{array}$ \\
\hline 4 & Primigravida & Pregnant for the first time & Yes/No \\
\hline 5 & Ethnicity & Ethnicity as written in identity card & $\begin{array}{l}\text { Malay } \\
\text { Chinese } \\
\text { Indian } \\
\text { Others }\end{array}$ \\
\hline 6 & Education level & Refers to the highest level of formal education & $\begin{array}{l}\text { No formal education } \\
\text { Primary school } \\
\text { Secondary school } \\
\text { Tertiary education }\end{array}$ \\
\hline 7 & Household income & $\begin{array}{l}\text { Combined household income according to the Department of Statistics Malaysia [38] catego- } \\
\text { rized into low income }\left(B 40^{b}\right) \text {, middle income }\left(\mathrm{M} 40^{C}\right) \text { and high income }\left(\mathrm{T}_{2} \mathrm{O}^{d}\right)\end{array}$ & $\begin{array}{l}\mathrm{B} 40^{\mathrm{b}}<\mathrm{RM} 4850 \\
\mathrm{M} 40^{\mathrm{c}} \mathrm{RM} 4850-\mathrm{RM} 10959 \\
\mathrm{~T} 20^{\mathrm{d}} \geq \mathrm{RM} 10960\end{array}$ \\
\hline 8 & Caloric intake per day & $\begin{array}{l}\text { Total energy intake in one day, measured by } 24 \text {-h dietary recall (a proxy to hyperemesis } \\
\text { gravidarum) }\end{array}$ & $\begin{array}{l}\text { Numerical in Kilocalorie } \\
\text { per day (kcal/day) }\end{array}$ \\
\hline 9 & $\mathrm{BMI}^{\mathrm{e}}$ at booking & Body mass index at booking at first trimester & Numerical in kg/m² \\
\hline 10 & Occupation & Occupation reported by subject at booking & $\begin{array}{l}\text { Public } \\
\text { Private } \\
\text { Self-employed } \\
\text { Housewife/Unemployed }\end{array}$ \\
\hline 11 & Husband's occupation & Husband's occupation reported by subject at booking & $\begin{array}{l}\text { Public } \\
\text { Private } \\
\text { Self-employed } \\
\text { Unemployed }\end{array}$ \\
\hline 12 & $\begin{array}{l}\text { Medical problem in } \\
\text { previous pregnancy }\end{array}$ & $\begin{array}{l}\text { Any medical problem or complications encountered during previous completed pregnancy } \\
\text { (gestational diabetes, hypertensive disorders, anemia in pregnancy etc.) }\end{array}$ & Yes/No \\
\hline 13 & History of miscarriage & Any experience of spontaneous pregnancy loss before completed 22 weeks of gestation & Yes/No \\
\hline 14 & Grand multigravida & Pregnant for the sixth time or more & Yes/No \\
\hline
\end{tabular}

a METs metabolic equivalents

b B40 - bottom 40\% earners in the population

c M40 - middle $40 \%$ earners in the population

${ }^{d}$ T20 - top 20\% earners in the population

e $B M I$ body mass index

Department, Ministry of Health Malaysia, available on their website.

Physical activity levels were calculated from the answers given in the PPAQ, presented in METs"hour per week. It was also classified by intensity - sedentary $(<1.5$ METs), light (1.5 to <3 METs), moderate (3-6 METs) and vigorous ( $>6 \mathrm{METs}$ ) - as well as by type/domain (household, sports, occupational, commuting and inactivity). The data were then classified as physically active or inactive to measure the prevalence of physical inactivity among the samples collected. Physical inactivity which was the dependent variable in this study was defined by less than 7.5 METs*hour per week which was equal to a total of at least $150 \mathrm{~min}$ of moderate to vigorous activities in a week [1].
The descriptive analysis was followed by simple and multiple logistic regressions to calculate the crude odds ratio and adjusted odds ratio (aOR) against the dependent variables in this study. In the multiple logistic regression analysis, all 13 independent variables included in this study were run and tested at once by using the ENTER method in SPSS version 22 to get the aOR and $p$ value of each variable.

Significant factors associated with physical inactivity were confirmed when $p<0.05$. This was followed by testing for interactions among the significant variables. Multicollinearity among the variables was also checked by looking at the standard errors of the significant variables in the final model. A value $<5.0$ would confirm than there was no multicollinearity between the significant variables 
[39]. All analyses were done using SPSS software version 22.

\section{Results}

A total of 339 pregnant mothers were sampled and participated in this study. All those who were approached agreed to take part, however, 23 respondents were withdrawn from the study. This was because 13 respondents failed to meet at least one of the inclusion criteria and four respondents were found to have met at least one of the exclusion criteria. Another six respondents were withdrawn due to not completing the questionnaire properly, especially in PPAQ section. Therefore, a total of 316 respondents were included in the final analysis (Fig. 2). A total of $27.5 \%$ came from Cheras district, $26.6 \%$ from Titiwangsa district, $7.6 \%$ from Lembah Pantai district and 38.3\% from Kepong district.

\section{Maternal characteristics and physical activity levels}

The maternal characteristics included in this study are presented in Table 2. The mean age of respondents was 29 years old, and they were predominantly Malay. Most of the respondents were married and fell into the low-income category. Only $6(2.1 \%)$ of them belonged to the high-income group (top $20 \%$ earners in the population); therefore, this group was merged with the middle-income group. For the education level variable, all respondents had formal education and only $2(0.6 \%)$ of the respondents fell under the primary education category. Therefore, the first three categories were merged, leaving only two categories in the final analysis, namely those who had had tertiary education $(68.4 \%)$ and those who had not (31.6\%). Few of the respondents had a history of miscarriage and medical illnesses in previous pregnancies such as gestational diabetes mellitus, anaemia in pregnancy or gestational hypertensive disorders.

Table 3 shows the total levels of physical activity among the pregnant mothers and further classified into domains and intensities of physical activity. The highest median activity was seen in the household domain - 92.5 METs"hour per week - followed by the occupational domain at 35.6 METs*hour per week. The lowest activity was detected in the sports/exercise domain. Besides, the pregnant mothers were also noted to spend more time doing light activities compared with moderate and vigorous activities. More than half of them met

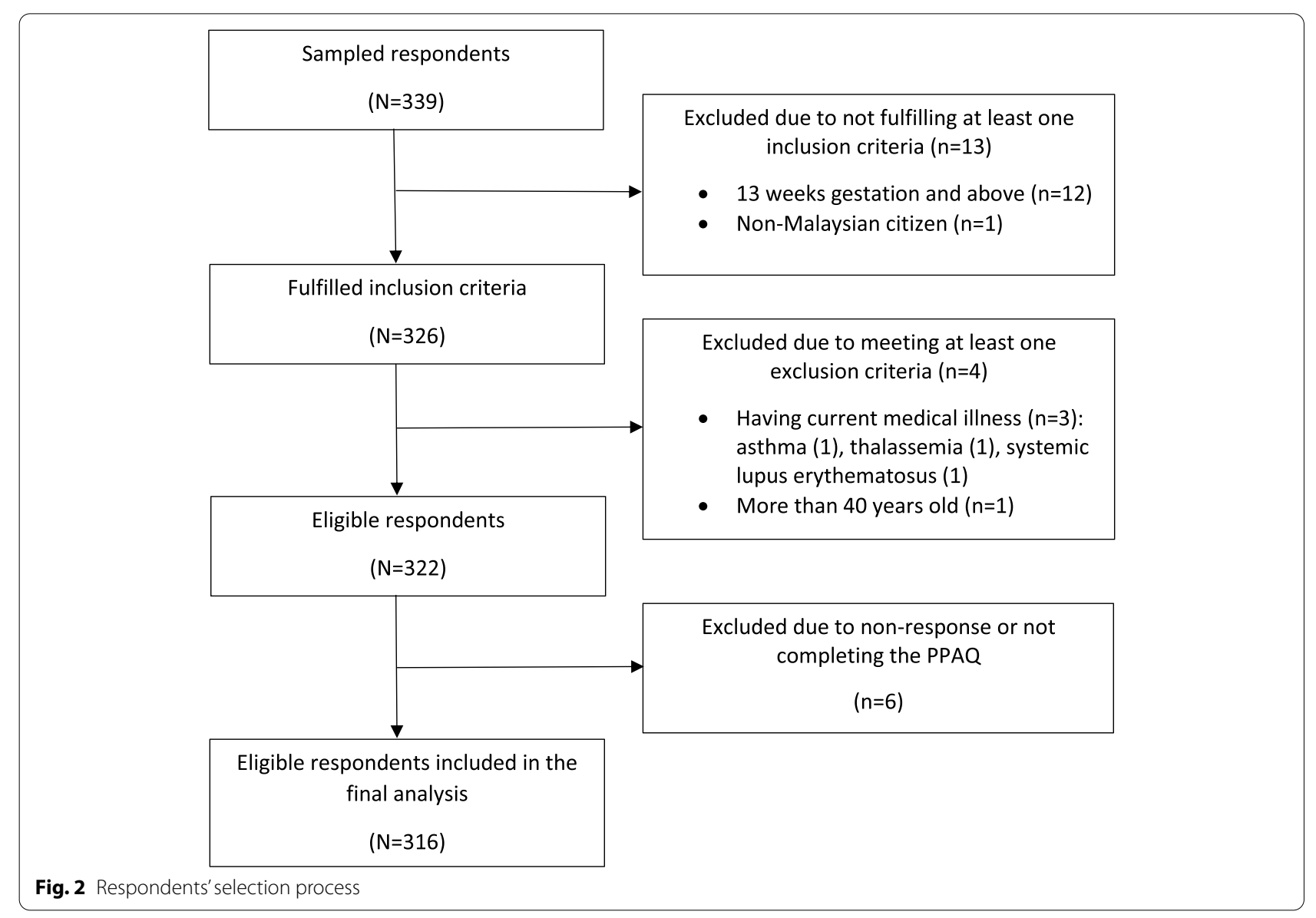


Table 2 Maternal characteristics of respondents

\begin{tabular}{|c|c|c|}
\hline Maternal characteristics & $\mathrm{N}(\%)$ & $\operatorname{Mean} \pm \mathrm{SD}^{\mathrm{a}}$ \\
\hline Age (year) & $316(100.0)$ & $29 \pm 4.3$ \\
\hline \multicolumn{3}{|l|}{ Ethnicity $(N=313)$} \\
\hline Malay & $251(80.2)$ & \\
\hline Chinese & $32(10.2)$ & \\
\hline Indian & $19(6.1)$ & \\
\hline Others & $11(3.5)$ & \\
\hline \multicolumn{3}{|l|}{ Occupation $(N=311)$} \\
\hline Public & $60(19.3)$ & \\
\hline Private & $157(50.5)$ & \\
\hline Self-employed & $17(5.4)$ & \\
\hline Housewife/Unemployed & $77(24.8)$ & \\
\hline \multicolumn{3}{|l|}{ Marital status $(N=310)$} \\
\hline Married & $294(94.8)$ & \\
\hline Unmarried & $16(5.2)$ & \\
\hline \multicolumn{3}{|l|}{ Education level $(N=316)$} \\
\hline No tertiary education ${ }^{b}$ & $100(31.6)$ & \\
\hline With tertiary education ${ }^{c}$ & $216(68.4)$ & \\
\hline \multicolumn{3}{|l|}{ Husband's occupation ( $N=308)$} \\
\hline Public & $68(22.1)$ & \\
\hline Private & $190(61.7)$ & \\
\hline Self-employed & $47(15.2)$ & \\
\hline Unemployed & $3(1.0)$ & \\
\hline \multicolumn{3}{|l|}{ Household income $(N=285)$} \\
\hline Low income (B40) & $167(58.6)$ & \\
\hline Middle income (M40) and higher & $118(41.4)$ & \\
\hline $\mathrm{BMI}^{\mathrm{d}}$ at booking $\left(\mathrm{kg} / \mathrm{m}^{2}\right)$ & $256(81.0)$ & $24.7 \pm 4.7$ \\
\hline \multicolumn{3}{|l|}{ History of miscarriage $(N=314)$} \\
\hline Yes & $17(5.4)$ & \\
\hline No & $297(94.6)$ & \\
\hline \multicolumn{3}{|c|}{ Medical problem in previous pregnancy $(N=316)$} \\
\hline Yes & $23(7.3)$ & \\
\hline No & $293(92.7)$ & \\
\hline \multicolumn{3}{|l|}{ Grand multigravida $(N=316)$} \\
\hline Yes & $11(3.5)$ & \\
\hline No & $305(96.5)$ & \\
\hline \multicolumn{3}{|l|}{ Primigravida $(N=316)$} \\
\hline Yes & $129(40.8)$ & \\
\hline No & $187(59.2)$ & \\
\hline Caloric intake per day (kcal) & $191(60.4)$ & $1297 \pm 350$ \\
\hline
\end{tabular}

Table 3 Physical activity levels among respondents

\begin{tabular}{|c|c|c|}
\hline Physical activity & N (\%) & Median (IQR $\left.{ }^{\mathrm{a}}\right)$ \\
\hline Total activity (METs ${ }^{\text {b*hour/week) }}$ & $316(100.0)$ & $183.3(188.8)$ \\
\hline \multicolumn{3}{|l|}{ By domain (METs ${ }^{\mathrm{b} *}$ hour/week): } \\
\hline Household activity & 314(99.4) & $92.5(123.6)$ \\
\hline Occupational activity & $237(75.0)$ & $35.6(76.7)$ \\
\hline Sports/Exercise activity & $215(68.0)$ & $0.9(3.9)$ \\
\hline Commuting activity & 295(93.4) & $10.7(18.1)$ \\
\hline Inactivity & 313(99.1) & $14.9(24.7)$ \\
\hline \multicolumn{3}{|l|}{ By intensity (METs ${ }^{\mathrm{b} *}$ hour/week): } \\
\hline Sedentary activity & $312(98.7)$ & $7.3(13.4)$ \\
\hline Light activity & $316(100.0)$ & $100.6(100.0)$ \\
\hline Moderate activity & $305(96.5)$ & $54.9(100.2)$ \\
\hline Vigorous activity & $83(26.3)$ & $0(0.8)$ \\
\hline \multicolumn{3}{|l|}{ Physically active $(N=316)$} \\
\hline Yes & $195(61.7)$ & \\
\hline No & $121(38.3)$ & \\
\hline
\end{tabular}

a IQR interquartile range

${ }^{\mathrm{b}}$ METs metabolic equivalents

c Those who involved in at least $150 \mathrm{~min}$ of moderate to vigorous activities in a week

the WHO minimum physical activity requirement of engaging in at least $150 \mathrm{~min}$ of moderate to vigorous activities. The prevalence of physical inactivity among these respondents was $38.3 \%$.

\section{Determinants of physical inactivity in pregnancy}

In the simple logistic regression, education level, BMI at booking and primigravida were significantly associated with physical inactivity. These three variables were also significant in the multivariable analysis (Table 4).

There were no interactions found between the three significant variables. The standard errors of all three significant variables were $<5.0$ in the final model; therefore, it was safe to conclude that multicollinearity did not exist among these variables [39]. The Nagelkerke $R$ square value was 0.226 , which meant that the three significant variables found in this study would explain $22.6 \%$ of the variation in physical inactivity in the final adjusted model.

\section{Discussion}

The observed prevalence of physical inactivity of $38.3 \%$ among pregnant women in this study is $10.0 \%$ higher compared with the general adult women population aged $\geq 16$ years in Malaysia in 2019 [22]. This was expected because pregnant women tend to reduce and limit their physical activities during pregnancy $[13,15,16,24]$. A possible explanation could be the belief that daily living 
Table 4 Simple and multiple logistic regressions to determine the factors associated with physical inactivity among pregnant mothers in Kuala Lumpur

\begin{tabular}{|c|c|c|c|c|c|c|}
\hline Variables & $\begin{array}{l}\text { Crude } \\
\text { OR }^{\mathrm{a}}\end{array}$ & $p$ value & $95 \% \mathrm{Cl}^{\mathrm{b}}$ & $\begin{array}{l}\text { Adjusted } \\
\mathrm{OR}^{\mathrm{a}}\end{array}$ & $p$ value & $95 \% \mathrm{Cl}^{\mathrm{b}}$ \\
\hline Age (year) & 0.97 & 0.19 & $0.92,1.02$ & 1.00 & 0.96 & $0.89,1.13$ \\
\hline Caloric intake per day (kcal) & 1.00 & 0.26 & $1.00,1.00$ & 1.00 & 0.07 & $1.00,1.00$ \\
\hline \multicolumn{7}{|l|}{ Ethnicity } \\
\hline Malay & 1.00 & & & 1.00 & & \\
\hline Chinese & 1.02 & 0.96 & $0.48,2.18$ & 1.68 & 0.44 & $0.45,6.24$ \\
\hline Indian & 1.89 & 0.18 & $0.74,4.81$ & 2.25 & 0.24 & $0.59,8.58$ \\
\hline Others & 2.04 & 0.25 & $0.61,6.87$ & 1.36 & 0.81 & $0.12,15.54$ \\
\hline \multicolumn{7}{|l|}{ Grand multigravida } \\
\hline Yes & 2.88 & 0.18 & $0.61,13.56$ & 3.16 & 0.34 & $0.30,33.87$ \\
\hline No & 1.00 & & & 1.00 & & \\
\hline \multicolumn{7}{|l|}{ Primigravida } \\
\hline Yes & 1.70 & $0.02^{*}$ & $1.07,2.70$ & 3.54 & $0.01 *$ & $1.40,8.97$ \\
\hline No & 1.00 & & & 1.00 & & \\
\hline \multicolumn{7}{|l|}{ Occupation } \\
\hline Public & 0.94 & 0.85 & $0.47,1.86$ & 2.84 & 0.32 & $0.36,22.38$ \\
\hline Private & 0.82 & 0.50 & $0.47,1.44$ & 1.33 & 0.58 & $0.48,3.69$ \\
\hline Self-employed & 0.77 & 0.63 & $0.26,2.29$ & 3.03 & 0.09 & $0.85,10.77$ \\
\hline Housewife/Unemployed & 1.00 & & & 1.00 & & \\
\hline \multicolumn{7}{|l|}{ Marital status } \\
\hline Married & 1.00 & & & 1.00 & & \\
\hline Unmarried & 1.28 & 0.63 & $0.46,3.54$ & 0.42 & 0.50 & $0.03,5.22$ \\
\hline \multicolumn{7}{|l|}{ Education level } \\
\hline No tertiary education ${ }^{c}$ & 1.70 & $0.03^{*}$ & $1.05,2.76$ & 3.77 & $0.01 *$ & $1.35,10.52$ \\
\hline With tertiary education $^{d}$ & 1.00 & & & 1.00 & & \\
\hline \multicolumn{7}{|l|}{ Husband's occupation } \\
\hline Public & 1.00 & & & 1.00 & & \\
\hline Private & 0.91 & 0.73 & $0.51,1.60$ & 1.34 & 0.57 & $0.48,3.72$ \\
\hline Self-employed & 1.03 & 0.93 & $0.48,2.20$ & 1.14 & 0.84 & $0.32,4.04$ \\
\hline Unemployed & 3.04 & 0.37 & $0.26,35.16$ & - & - & - \\
\hline \multicolumn{7}{|l|}{ Household income } \\
\hline Low income (B40 ${ }^{\mathrm{e}}$ ) & 1.31 & 0.29 & $0.80,2.14$ & 0.96 & 0.93 & $0.40,2.32$ \\
\hline Middle income $\left(\mathrm{M} 40^{f}\right)$ or higher & 1.00 & & & 1.00 & & \\
\hline $\mathrm{BMI}^{\mathrm{g}}$ at booking & 0.92 & $0.01 *$ & $0.86,0.97$ & 0.88 & $0.01 *$ & $0.80,0.97$ \\
\hline \multicolumn{7}{|l|}{ History of miscarriage } \\
\hline Yes & 1.00 & & & 1.00 & & \\
\hline No & 2.08 & 0.21 & $0.15,1.51$ & 0.15 & 0.10 & $0.02,1.45$ \\
\hline \multicolumn{7}{|c|}{ Medical problem in previous pregnancy } \\
\hline Yes & 1.00 & & & 1.00 & & \\
\hline No & 1.83 & 0.22 & $0.70,4.78$ & 0.64 & 0.59 & $0.13,3.17$ \\
\hline
\end{tabular}

a $O R$ odds ratio

${ }^{b} \mathrm{Cl}$ confidence interval

c formal education of 12 years or less

${ }^{d}$ formal education of more than 12 years

e B40 - bottom 40\% earners in the population

${ }^{f}$ M40 - middle $40 \%$ earners in the population

g $B M /$ body mass index

* Significant at $p<0.05$

Nagelkerke R square 0.226 
activities provide sufficient exercise and that resting is preferred over being active due to the perceived health and safety risks to both mother and foetus while participating in sports and exercises [40]. Moreover, tiredness and pain have been reported as reasons for pregnant women to be inactive [24]. The prevalence of physical inactivity in this study, however, is much lower than the findings from another study in Malaysia, which was conducted in the neighbouring state of Negeri Sembilan. In that study, the prevalence of physical inactivity was as high as $60.4-71.9 \%$, but the sample also comprised those in the second and third trimester of pregnancy, a factor that might explain the higher physical inactivity [21]. Another study conducted among pregnant women in Kuantan, Pahang, Malaysia, reported an even higher physical inactivity prevalence of 78.6\% [41]. However, it was worth noting that the researchers used a different questionnaire, namely the Malay and short version of the International Physical Activity Questionnaire (IPAQ) instead of the PPAQ that was used in this study. The prevalence of physical inactivity was also noted to be higher among pregnant women in Brazil and Vietnam - 48.2 and $79.4 \%$, respectively $[15,18]$. It was particularly high in the study in Vietnam because the criterion applied to be physically active was 150 min per week of moderate to vigorous activities in the sports/exercise category only. In a study among pregnant women in Serbia, another middle-income country, the prevalence of physical inactivity was $11 \%$ lower than that reported in this study [20]. A study done in Ethiopia, a low-income country, reported an even lower physical inactivity prevalence of $21.9 \%$ [17]. These data are consistent with pooled worldwide data showing that the prevalence of physical inactivity is twice as high in higher compared with lower income countries [12].

The median of the total energy expenditure among pregnant women in this study is in the range of the reported mean/median total energy expenditure among pregnant women in previous studies from different countries, ranging from 123.2 METs*hour/week in Vietnam to 270.9 METs*hour/week in Portugal [16, 18, 27, 42-44]. At 183.3 METs"hour per week, the median total energy expenditure value in this study is almost the same as the findings among urban pregnant women in the state of Selangor, which surrounds the federal city of Kuala Lumpur geographically [45]. The pregnant women in our study spent most of their time doing moderate-intensity activities at home, even though most of them were working and only $24.8 \%$ of them were housewives or unemployed. This was evident because the household domain had the highest energy expenditure followed by occupational domain, whereas the sports/exercise domain had the lowest energy expenditure. Kaur et al. [45] found that the highest activity among urban pregnant women in Selangor was also in the household category. However, it was slightly lower at $76 \mathrm{METs*hour/week} \mathrm{compared}$ with the findings in this study. Moreover, studies in other parts of the world have also reported the highest activity in the household category $[16,18,31,46]$. However, there were two studies which had found that occupational category had the highest energy expenditure in the first trimester but subsequently declined in the second trimester $[27,42]$. Although high household activities among pregnant women have been a common theme in previous studies, it was worth investigating this category further because this study was conducted during the COVID19 pandemic. Unforeseen circumstances like lockdowns and movement control orders imposed by the authorities of Malaysia - which resulted in new norms such as working from home and avoiding public spaces like gyms and antenatal classes, etc. - might be one of the explanations as to why this pattern emerged in this study. Furthermore, Kuala Lumpur was one of the states hit hardest by the COVID-19 outbreak in Malaysia [47]. This could well explain the low activity seen in the occupational and commuting category as most respondents spent the majority of their time at home, including working from home, instead of going out.

In this study, those who were primigravida were more likely to be physically inactive compared with those who were multigravida. Inexperienced first-time pregnant women might be extra cautious and mindful about their pregnancy and thus avoid sports and recreational activities, even when they have the time for these activities, compared with their counterparts who have to spend the bulk of their time caring for their living children. The concern for engaging in moderate and vigorous activities was evident in studies by Todorovic et al. [20] and Merkx et al. [14], in which women who were involved in light activities such as walking at a slow pace were more likely to continue this activity while those who used to be involved in moderate to vigorous activities were inclined to discontinue the practice entirely once they became pregnant.

Education level was another significant factor contributing to physical inactivity in this study in which, those who had no tertiary education $(\leq 12$ years of formal education) were more likely to be physically inactive. This is consistent with the findings by Lindqvist et al. [34] and also Todorovic et al. [20], in which those who had $<12$ years of formal education were more likely to be physically inactive. Another study also found that illiteracy or no formal education was associated with higher physical inactivity [17]. Women with higher education could be more aware of the benefits of physical activity in pregnancy due to a greater 
ability to seek and process information given to them by health care providers. This finding emphasises the need to use simple language and terminology in physical activity educational programs as well as in promotional tools and instruments such as infographics, posters, leaflets and pamphlets, among others.

BMI at booking is a modifiable factor that was significantly associated with physical inactivity in this study. Those with lower BMI were more likely to be physically inactive. However, a previous study by Lindqvist et al. [34] reported a different result: those with a higher BMI were more likely to be inactive. Two other studies did not find BMI to be significantly associated with physical activity levels $[15,20]$, while Santo et al. [35] found that those who were underweight were more likely to be physically active compared with those with normal BMI. Further research is needed to extrapolate the inconsistencies with findings related to BMI.

There was no association between physical inactivity and maternal occupation found in this study as well as maternal age, although the NHMS 2019 reported a significant increase in physical inactivity level with age in the general adult population. However, that was only applied to the age group of 55-59 years to 75 years and above [22]. Past studies among pregnant women have also not seen any association with age $[15,19,20,30,31$, 33-35]. However Gebregziabher et al. [17] found that those who were less than 19 years of age were four times more likely to be physically inactive (aOR $4.7,95 \%$ CI $1.4,15.3)$ compared with those who were in 25-29-year age group. A study by Steinl et al. [32] among pregnant teenagers also noted a positive correlation between age and physical activity levels. However, this current study did not include teenage pregnancies because they are considered to be high risk.

It is also worth noting that those who had history of miscarriage or medical illness in previous pregnancies had no effect on physical activity levels in this study. This is in contrast to the findings by Gebregziabhe et al. [17], in which past miscarriage experience was found to be a barrier to being physically active in the current pregnancy. Therefore, it was worth studying whether healthy pregnant women with a history of miscarriage or medical illness perceive physical activity as highly associated with foetal and newborn morbidity and mortality when in fact it is highly unlikely, as has been reported by Davenport et al. [4].

\section{Strengths and limitations}

There were only two studies that targeted the subpopulation of pregnant women in Malaysia between 1980 and 2019 . This constituted only $0.6 \%$ of the total research on physical activity conducted in Malaysia within that period of time [48]. To the best of our knowledge, this was the first study assessing the physical inactivity levels among pregnant women in the most urbanised city of Kuala Lumpur.

This study used a specific questionnaire to measure physical activity levels in pregnancy, the Malay version of the PPAQ [36], which was first developed by Chasan-Taber et al. [37]. This questionnaire has been validated and translated into many languages and used around the world, making the comparison of findings of similar studies more standardised. However, using a self-administered questionnaire instead of an objective measurement tool such as accelerometer or pedometer could pose limitations such as information bias. Another limitation of this study is the convenience sampling used during data collection; hence, the results could not be generalised to the entire population of Kuala Lumpur. This was partly due to the unprecedented COVID-19 outbreak in the middle of the study, a factor that made it more difficult to continue sampling and collecting data using a stricter and more rigorous method.

\section{Conclusion}

The prevalence of physical inactivity among pregnant women in their first trimester in Kuala Lumpur was $38.3 \%$. The highest energy expenditure was seen in the household category, followed by the occupational category, whereas the sports/exercise category had the lowest energy expenditure, most likely due to these respondents spending their time isolating at home. There were little to no participation observed in the vigorous intensity category. Factors associated with physical inactivity were primigravida, BMI at booking and education level.

From the results of this study, it is recommended that health education and interventional programs on physical activity among pregnant women in their first trimester should be targeted and focused on those who are primigravida and have no tertiary education $(\leq 12$ years of formal education). The educational content and materials should be updated and tailored to the current COVID-19 pandemic situation in which self-isolation, working from home and social distancing are the new norms. This can be done by advocating for more homebased, moderate to vigorous intensity activities without using expensive pieces of exercising equipment.

\section{Abbreviations}

aOR: Adjusted odds ratio; Cl: Confidence interval; PPAQ: Pregnancy physical activity questionnaire; BMI: Body mass index; METs: Metabolic equivalents; MET: Metabolic equivalent of task; WHO: World Health Organization; $\mathrm{MCH}$ : 
Maternal and child health; SD: Standard deviation; IQR: Interquartile range; B40: Bottom 40\% earners; M40: Middle 40\% earners; T20: Top 20\% earners; IPAQ: International physical activity questionnaire.

\section{Acknowledgements}

We would like to express our gratitude to the Ministry of Health staffs under the State Health Department of Federal Territory of Kuala Lumpur and Putrajaya for their contribution to the completion and success of this study. We also would like to thank the Director General of Health for his permission to publish this article.

\section{Authors' contributions}

SFSN was responsible for this study conception and design as well as analysis and interpretation of the data. The drafting of this article was also contributed by SFSN. IBI and ZMI was responsible for critical revision of this article for important intellectual content. All authors read and approved the manuscript.

\section{Funding}

This research was funded by Universiti Kebangsaan Malaysia with project code number: FF-2019-172.

\section{Availability of data and materials}

The datasets used and/or analysed during the current study are not publicly available in order to ensure participants' privacy and confidentiality but are available from the corresponding author on reasonable request, with the permission from the Director General of Health, Malaysia.

\section{Declarations}

\section{Ethics approval and consent to participate}

This study was registered with National Medical Research Register with the ID number: NMRR-19-71-46144 and approved by the Medical Research and Ethics Committee (MREC), Ministry of Health Malaysia (KKM/NIHSEC/P19-311(11)) and Research Ethics Committee of Universiti Kebangsaan Malaysia with reference number: UKM PPI/111/8/JEP-2019-226. All methods were performed in accordance with the relevant guidelines and regulations set by the committee and all participants provided written informed consent to participate in the study prior to data collection.

\section{Consent for publication}

Not applicable.

\section{Competing interests}

The authors declare that they have no competing interests.

\section{Author details}

${ }^{1}$ Department of Community Health, Faculty of Medicine, Universiti Kebangsaan Malaysia, Jalan Yaacob Latif, Bandar Tun Razak, Batu 9 Cheras, 56000 Wilayah Persekutuan Kuala Lumpur, Malaysia. ${ }^{2}$ Training Management Division, Ministry of Health Malaysia, Kompleks E, Pusat Pentadbiran Kerajaan Persekutuan, 62590 Wilayah Persekutuan Putrajaya, Malaysia.

Received: 28 June 2021 Accepted: 5 January 2022

Published online: 13 January 2022

\section{References}

1. WHO. Physical activity Geneva, Switzerland: WHO; 2020 [updated 26 November 2020. Available from: https://www.who.int/news-room/factsheets/detail/physical-activity.

2. Roland J. What exactly are METs, and what should you know about them? : Healthline; 2019 [updated 21 October 2019. Available from: https:// www.healthline.com/health/what-are-mets.

3. Mottola MF, Davenport MH, Ruchat S-M, Davies GA, Poitras VJ, Gray CE, et al. 2019 Canadian guideline for physical activity throughout pregnancy. Br J Sports Med. 2018;52(21):1339-46.

4. Davenport MH, Kathol AJ, Mottola MF, Skow RJ, Meah VL, Poitras VJ, et al. Prenatal exercise is not associated with fetal mortality: a systematic review and meta-analysis. Br J Sports Med. 2019;53(2):108-15.
5. Dipietro L, Evenson KR, Bloodgood B, Sprow K, Troiano RP, Piercy KL, et al. Benefits of physical activity during pregnancy and postpartum: an umbrella review. Med Sci Sports Exerc. 2019;51(6):1292-302.

6. Nakamura A, van der Waerden J, Melchior M, Bolze C, El-Khoury F, Pryor L. Physical activity during pregnancy and postpartum depression: systematic review and meta-analysis. J Affect Disord. 2019;246:29-41.

7. Davenport MH, McCurdy AP, Mottola MF, Skow RJ, Meah VL, Poitras VJ, et al. Impact of prenatal exercise on both prenatal and postnatal anxiety and depressive symptoms: a systematic review and meta-analysis. $\mathrm{Br} \mathrm{J}$ Sports Med. 2018;52(21):1376-85.

8. Davenport MH, Ruchat SM, Poitras VJ, Jaramillo Garcia A, Gray CE, Barrowman N, et al. Prenatal exercise for the prevention of gestational diabetes mellitus and hypertensive disorders of pregnancy: a systematic review and meta-analysis. Br J Sports Med. 2018;52(21):1367-75.

9. Ruchat SM, Mottola MF, Skow RJ, Nagpal TS, Meah VL, James M, et al. Effectiveness of exercise interventions in the prevention of excessive gestational weight gain and postpartum weight retention: a systematic review and meta-analysis. Br J Sports Med. 2018;52(21):1347-56.

10. WHO. Global action plan on physical activity 2018-2030: more active people for a healthier world. Geneva: World Health Organization; 2018. p. 101.

11. Sallis JF, Bull F, Burdett R, Frank LD, Griffiths P, Giles-Corti B, et al. Use of science to guide city planning policy and practice: how to achieve healthy and sustainable future cities. Lancet. 2016;388(10062):2936-47.

12. Guthold R, Stevens GA, Riley LM, Bull FC. Worldwide trends in insufficient physical activity from 2001 to 2016: a pooled analysis of 358 population-based surveys with 1.9 million participants. Lancet Glob Health. 2018;6(10):E1077-E86.

13. Garland M. Physical activity during pregnancy: prescription for improved perinatal outcomes. J Nurse Pract. 2017;13(1):54-8.

14. Merkx A, Ausems M, Bude L, de Vries R, Nieuwenhuijze MJ. Factors affecting perceived change in physical activity in pregnancy. Midwifery. 2017;51:16-23.

15. Nascimento SL, Surita FG, Godoy AC, Kasawara KT, Morais SS. Physical activity patterns and factors related to exercise during pregnancy: a cross sectional study. PLoS One. 2015;10(6):e0128953.

16. Santos PC, Abreu S, Moreira C, Santos R, Ferreira M, Alves O, et al. Physical Activity Patterns During Pregnancy in a Sample of Portuguese Women: A Longitudinal Prospective Study. Iran Red Crescent Med J. 2016;18(3):e22455-e.

17. Gebregziabher D, Berhe H, Kassa M, Berhanie E. Level of physical activity and associated factors during pregnancy among women who gave birth in public zonal hospitals of Tigray. BMC Res Notes. 2019;12(1):454.

18. Nguyen CL, Pham NM, Lee AH, Nguyen PTH, Chu TK, Ha AVV, et al. Physical activity during pregnancy is associated with a lower prevalence of gestational diabetes mellitus in Vietnam. Acta Diabetol. 2018;55(9):955-62.

19. Richardsen KR, Falk RS, Jenum AK, Mørkrid K, Martinsen EW, Ommundsen $Y$, et al. Predicting who fails to meet the physical activity guideline in pregnancy: a prospective study of objectively recorded physical activity in a population-based multi-ethnic cohort. BMC Pregnancy Childbirth. 2016;16(1):186.

20. Todorovic J, Terzic-Supic Z, Bjegovic-Mikanovic V, Piperac P, Dugalic S, Gojnic-Dugalic M. Factors associated with the leisure-time physical activity (LTPA) during the first trimester of the pregnancy: the cross-sectional study among pregnant women in Serbia. Int J Environ Res Public Health. 2020;17(4):1366.

21. Yong HY, Mohd Shariff Z, Mohd Yusof BN, Rejali Z, Bindels J, Tee YYS, et al. High physical activity and high sedentary behavior increased the risk of gestational diabetes mellitus among women with excessive gestational weight gain: a prospective study. BMC Pregnancy Childbirth. 2020;20(1):597.

22. Institute for Public Health Malaysia. National Health and Morbidity Survey (NHMS) 2019. Shah Alam, Selangor, Malaysia: National Institutes of Health, Ministry of Health, Malaysia; 2020.

23. Su TT, Azzani M, Adewale AP, Thangiah N, Zainol R, Majid H. Physical activity and health-related quality of life among low-income adults in metropolitan Kuala Lumpur. J Epidemiol. 2019;29(2):43-9.

24. Merkx A, Ausems M, Budé L, de Vries R, Nieuwenhuijze MJ. Weight gain in healthy pregnant women in relation to pre-pregnancy BMI, diet and physical activity. Midwifery. 2015;31(7):693-701. 
25. Catov JM, Parker CB, Gibbs BB, Bann CM, Carper B, Silver RM, et al. Patterns of leisure-time physical activity across pregnancy and adverse pregnancy outcomes. Int J Behav Nutr Phys Act. 2018;15(1):68.

26. Baker $\mathrm{JH}$, Rothenberger SD, Kline CE, Okun ML. Exercise during early pregnancy is associated with greater sleep continuity. Behav Sleep Med. 2018;16(5):482-93.

27. Bisson M, Croteau J, Guinhouya BC, Bujold E, Audibert F, Fraser WD, et al. Physical activity during pregnancy and infant's birth weight: results from the 3D birth cohort. BMJ Open Sport Exerc Med. 2017:3(1):e000242.

28. Cohen TR, Plourde H, Koski KG. Use of the pregnancy physical activity questionnaire (PPAQ) to identify behaviors associated with appropriate gestational weight gain during pregnancy. J Phys Act Health. 2013;10(7):1000-7.

29. Lindqvist M, Persson M, Mogren I. "Longing for individual recognition" - pregnant women's experiences of midwives' counselling on physical activity during pregnancy. Sex Reprod Healthc. 2018;15:46-53.

30. Mendinueta A, Esnal H, Arrieta H, Arrue M, Urbieta N, Ubillos I, et al. What accounts for physical activity during pregnancy? A study on the Sociodemographic predictors of self-reported and objectively assessed physical activity during the 1st and 2nd trimesters of pregnancy. Int J Environ Res Public Health. 2020;17(7):2517.

31. Oyeyemi A, Lawan A, Oyeyemi A, Awotidebe W. Patterns and predictors of physical activity among pregnant women in Northeast Nigeria. Afr J Phys Act Health Sci. 2017;23(4):549-62.

32. Steinl GK, Whisner CM, Pressman EK, Cooper EM, Groth SW, O'Brien KO. Patterns and correlates of self-reported physical activity in a cohort of racially diverse pregnant adolescents. J Pediatr Adolesc Gynecol. 2019;32(1):51-6.

33. Yun-li C, Hai-hui M, Ying-jie S, Yong-le Z, Liang-kun M, Yu J. The status and influencing factors of physical activity among Chinese pregnant women during different pregnancies. Chin J Dis Control Prev. 2021;25(2):149.

34. Lindqvist $M$, Lindkvist $M$, Eurenius $E$, Persson $M$, Ivarsson A, Mogren I. Leisure time physical activity among pregnant women and its associations with maternal characteristics and pregnancy outcomes. Sex Reprod Healthc. 2016:9:14-20.

35. Santo EC, Forbes PW, Oken E, Belfort MB. Determinants of physical activity frequency and provider advice during pregnancy. BMC Pregnancy Childbirth. 2017;17(1):286.

36. Mohamad P-S, Abdul Jalil R, Kah LS, Tengku Ismail TA, Hamid NAA, Wan NikWS, et al. Linguistic Translation and Cross-Cultural Adaptation of the Pregnancy Physical Activity Questionnaire (PPAQ) for Malaysian Women. In: Contemporary research in sports, exercise and health: measurement and protocol [internet]. New York: Nova Science PublishersSports and Athletics Preparation, Performance and Psychology; 2021. [43-64].

37. Chasan-Taber L, Schmidt MD, Roberts DE, Hosmer D, Markenson G, Freedson PS. Development and validation of a pregnancy physical activity questionnaire. Med Sci Sports Exerc. 2004;36(10):1750-60.

38. Department of Statistics Malaysia. Household income and basic amenities survey report 2019. Putrajaya Malaysia: Department of Statistics Malaysia; 2020.

39. Chan YH. Biostatistics 202: logistics regression analysis. Singap Med J. 2004;45(4):5.

40. Ahmad N, Syed Nor SF, Daud F. Understanding myths in pregnancy and childbirth and the potential adverse consequences: a systematic review. Malays J Med Sci. 2019;26(4):17-27.

41. Aslam F, Abd Aziz KH, Jamani NA, Mohd RR. Level of physical activity and It's associated factors among pregnant women during pregnancy. Int J Allied Health Sci. 2021;5(1):2108.

42. Lee CF, Hwang FM, Lin HM, Chi LK, Chien LY. The physical activity patterns of pregnant Taiwanese women. J Nurs Res. 2016;24(4):291-9.

43. Antosiak-Cyrak KZ, Demuth A. A study of physical activity levels of pregnant women using the polish version of pregnancy physical activity questionnaire (PPAQ-PI). Ginekol Pol. 2019;90(5):250-5.

44. Aburezq M, AlAlban F, Alabdulrazzaq M, Badr H. Risk factors associated with gestational diabetes mellitus: the role of pregnancy-induced hypertension and physical inactivity. Pregnancy Hypertens. 2020;22:64-70.

45. Kaur S, Ng CM, Badon SE, Jalil RA, Maykanathan D, Yim HS, et al. Risk factors for low birth weight among rural and urban Malaysian women. BMC Public Health. 2019;19(4):539.
46. Hoodbhoy Z, Qureshi RN, lqbal R, Muhabat Q. Household chores as the main source of physical activity: perspectives of pregnant Pakistani women. J Pak Med Assoc. 2018;68(4):565-9.

47. Kenyataan Akhbar KPK 1 Mei 2021 - Situasi Semasa Jangkitan Penyakit Coronavirus 2019 (COVID-19) di Malaysia [press release]. Ministry of Health Malaysia, 1 May 20212021.

48. Khoo S, Poh BK, Suhaimi SA, Chong KH, Ramirez VA. Physical Activity Promotion in Malaysia: Challenges and Opportunities. Front Public Health. 2020;8:536239.

\section{Publisher's Note}

Springer Nature remains neutral with regard to jurisdictional claims in published maps and institutional affiliations.

Ready to submit your research? Choose BMC and benefit from

- fast, convenient online submission

- thorough peer review by experienced researchers in your field

- rapid publication on acceptance

- support for research data, including large and complex data types

- gold Open Access which fosters wider collaboration and increased citations

- maximum visibility for your research: over 100M website views per year

At BMC, research is always in progress.

Learn more biomedcentral.com/submissions 